\title{
Relationship between Hemorrhagic Stroke and Mortality in Chronic Complex Outpatients: Results from a Community Cohort of Patients
}

González-Henares $\mathbf{M A}^{1,2}$, Clua-Espuny $\mathrm{JL}^{2,3^{*}}$, Queralt-Tomas $\mathbf{M L L}^{4}$, Campo-Tamayo $\mathbf{W}^{5}$, Muria-Subirats $\mathbf{E}^{5}$, Panisello-Tafalla $\mathbf{A}^{6}$, Lucas-Noll $\mathbf{J}^{7}$, ForcadellArenas $\mathrm{T}^{8}$ and Gil-Guillen VF ${ }^{9}$

${ }^{1} E A P-C a m a r l e s-A l d e a-A m p o l l a$, Catalonian Health Institute, SAP Terres de l'Ebre, Health Department, Generalitat de Catalunya, CAP Ampolla, 43895 Tortosa, Spain

${ }^{2}$ Department of Research, ICS Terres de l'Ebre, Research Institute University Primary Care (IDIAP) Jordi Gol, Spain

${ }^{3} E A P$ Tortosa 1-Est, Catalonian Health Institute, SAP Terres de l'Ebre, Health Department, Generalitat de Catalunya, CAP Temple, 43500 Tortosa, Spain

${ }^{4} E A P$ Tortosa-2-Oest, SAP Terres de l'Ebre, Health Department, Generalitat de Catalunya, Catalonian Health Institute, CAP Xerta, 43592 Spain

${ }^{5}$ UUDD Tortosa-Terres de l'Ebre, Resident Medicina Familiary Comunitaria, CAP Temple, EAP Tortosa Est, Institut Català de la Salut. Tortosa 43500, Spain

${ }^{6}$ EAP-Camarles-Aldea-Ampolla, Catalonian Health Institute, SAP Terres de l'Ebre, Health Department, Generalitat de Catalunya, CAP Camarles, 43894 Tortosa, Spain

${ }^{7} E A P-A l c a n a r-S t$ Carlos de la Rápita, Catalonian Health Institute, SAP Terres de l'Ebre, Health Department, Generalitat de Catalunya, CAP St Carles de la Rápita, 43894 Tortosa, Spain

${ }^{8}$ EAP Tortosa 1-Est, Catalonian Health Institute, SAP Terres de l'Ebre, Health Department, Generalitat de Catalunya, CAP Temple, 43500 Tortosa, Spain

${ }^{9}$ Cátedra Medicina de Familia, Universidad Miguel Hernández, 03202 Elche, Spain

*Corresponding author: Clua-Espuny JL, EAP-Tortosa Est, Institut Català Salut, SAP Terres de l'Ebre, Health Department, Generalitat de Catalunya, Plaça Carrilet, s/núm Tortosa 43500 Spain, Spain, Tel: +(34)-977 510018; Fax: +(34)-977445728; E-mail: jlclua.ebre.ics@gencat.cat

Received date: April 22, 2017; Accepted date: May 15, 2017; Published date: May 17, 2017

Copyright: ( 2017 González-Henares MA, et al. This is an open-access article distributed under the terms of the Creative Commons Attribution License, which permits unrestricted use, distribution, and reproduction in any medium, provided the original author and source are credited.

\begin{abstract}
Question: Around 3-5\% of people can be identified as chronic complex patients(CCP) and are increasingly at risk of hemorrhagic stroke.The main objective was to explore differences in risk factors and the association with outcome factors on mortality.

Materials and Methods: Multicenter and prospective cohort study from January 12013 to September 302016 among patients registered as chronic complex outpatients. To predict hazard ratios, mean survival time, and survival probabilities, multivariate Cox regression was used.

Results: 932 CCP were included (52.3\% women). Average age was 82.5 years $(95 \% \mathrm{Cl} 81.8-83.2)$. During a mean follow-up period of 2.8 years, $65(6.98 \%)$ stroke episodes happened (37 (56.9\%) ischemic; $28(43.1 \%)$ hemorrhagic). The percentage of $\mathrm{ICH}$ almost doubled $(21.0 \%$ to 43.1$)$ after CCP diagnosis; $26.1 \%$ had polypharmacy $(\geq 10), 57.6 \%$ VKA-treated patientsshowed TTR $<60 \%$, and had a higher incidence of falling $(31.9 \%$ vs. $19.2 \%, \mathrm{p} 0.002)$. The average survival time was significantly shorter associated with age $(\mathrm{HR} 1.0395 \% \mathrm{Cl}$ 1.14-1.53, p 0.001), previous stroke (HR 13.54 95\%, Cl 9.23-19.81, $\mathrm{p}<0.001)$, antiagreggant treatment (HR 1.97 $95 \% \mathrm{Cl} 1.21-3.21, \mathrm{p} 0.006$ ), anticoagulant treatment (HR $1.7895 \%$, Cl 1.22-2.60, p 0.002), and Barthel score $<60$ (HR 1.43 95\% Cl 1.04-1.97, p 0.024).
\end{abstract}

Conclusions: Given the co-occurrence of hemorrhagic strokes with poor performance status, multi-morbidity, and polypharmacy, multi-dimensional interventions are needed to improve health outcomes.

Keywords: Hemorrhagic stroke; Chronic complex patient; Mortality; Fall risk; Disability

Abbreviations: ADL: Activities of Daily Living; BP: Blood Pressure; CCP: Chronic and Complex Patient; DDD: Defined Daily Dose; HR: Hazard Risk; ICH: Intracerebral Hemorrhage; IDIAP: Primary Care Research Institute Jordi Gol Gurina; PIIC: Shared Individual Intervention Plan (Pla d'Intervenció Individualitzat Compartit (PIIC)); SBP: Systolic Blood Pressure; SD: Standard Deviation; SSRI: Selective Serotonin Reuptake Inhibitor; TTR: Time in Therapeutic Range

\section{Introduction}

We face an epidemic of multi-morbidity and rising complexity of health needs $[1,2]$ resulting from changing demographics and global circumstances. In developed countries, around 3-5\% of the people can be identified as chronic complex patients who are increasingly at risk of stroke $[3,4]$. Although the European population aged $\geq 65$ years will double by 2050 , there are few studies about the epidemiology of hemorrhagic stroke and the burden of unfavourable outcome and associated health care costs. The statistics about hemorrhagic stroke show high variability: lowering [3,5] against rising of incidence [6,7], or no change $[8,9]$. However, there is general agreement on the increase related to aging [10].

Unfortunately the intracerebral haemorrhage accounts for the shortest term survival and poor functional prognosis of all stroke types $[11,12]$. The prevention of these negative effects is of major importance because, nowadays, they are major issues for health and social care providers and the identification of patients likely to recover may be 
Citation: González-Henares MA, Clua-Espuny JL, Queralt-Tomas MLL, Campo-Tamayo W, Muria-Subirats E, et al. (2017) Relationship between Hemorrhagic Stroke and Mortality in Chronic Complex Outpatients: Results from a Community Cohort of Patients. J Aging Sci 5: 180. doi:10.4172/2329-8847.1000180

Page 2 of 9

crucial for families confronted with a need for intensive care and medical teams with regard to direction of care [13-15]. Over the last 20-30 years, problems related to aging and hemorrhagic stroke have become a prominent issue in global healthcare, there is no recent evidence on long term survival among chronic and complex people [16-18], and in spite of existing tools to predict mortality and functional outcome there are important limitations to their application [19].

The goals of the present analysis were (i) to improve our knowledge of the epidemiology of hemorrhagic stroke and mortality risk among people registered as chronic complex outpatients and (ii) to explore risk factors differences in the association of outcome factors on survival. This review discusses how primary care might tackle these new challenges of hemorrhagic stroke among the aging population.

\section{Materials and Methods}

We carried out a multicenter and prospective cohort study of the incidence of mortality from January 1, 2013 to September 30, 2016 among chronic complex outpatients (CCP) attending primary care teams in the Terres de l'Ebre health area in Catalonia (Spain). All people were managed by the public health system in Catalonia. Registry information was collected from the government-run healthcare provider responsible for all inpatient care in the county. The overall number of CCP registered was 3,490 people. We included a randomized sample of 932 adult patients registered in the electronic health records of primary care as CCP in the period from January 1 2013 December 31 2014. Patients were excluded if they resided in a long-term institutional setting. Alpha Risk=0.05; Precision $=0.03$.

Patient outcomes were followed until death or the end of the study (September 30, 2016) starting with the reporting date as CCP in the electronic health record. Data included demographics, functional, comorbidity, cognitive and social assessment, and were collected directly from the Shared Individual Intervention Plan [Pla d'intervenció individualitzat compartit (PIIC)] written and managed by the nursing service in primary care. In the PIIC, determinants related to personal factors, as well as the social and physical environment are described to provide a tailored personal approach according to the patient's preferences in the case of hospital readmission or emergency care use and the primary caregiver. The report is updated automatically to ensure that relevant information is shared across the electronic health record. Currently, $82 \%$ of people registered as CCP have this basic information in their PIIC.

\section{Definitions}

\section{Chronic complex patient (CCP)}

Definition: Those who meet at least four of the following criteria. Age ( $\geq 65$ years old). Chronic comorbidities $(\geq 4)$. Psychosocial disorders (cognitive impairment or psychological disorder with functional disability). Geriatric conditions such as functional disability (Barthel score $<55$, living in an assisted living facility, nursing home, or with in-home caregivers) or recurrent falls or fall risk. Previous high health care utilization (two unplanned hospitalizations for exacerbation of chronic pathologies or three emergency department visits in the last year). Number of active medications in the last six months ( $\geq 4$ active medications). Living alone or with a caregiver $\geq 75$ years old. The chronic complex patient [15] has been defined as a person with a chronic illness and complex clinical situations which make their management significantly far more difficult. The group also could include patients who do not meet these criteria, but are affected by other clearly complex conditions, such as schizophrenia or mental illnesses with behavioral disorders.

\section{Stroke}

Individuals with current stroke diagnoses in their medical charts after inclusion into the study were considered to have experienced an incident stroke. A previous stroke was considered to be present if the medical charts included a stroke diagnosis or if the individual, a caregiver, or a relative reported the diagnosis and it was found with supporting information on medical charts or other assessments. Records of inpatient care after baseline assessment with International Classification of Diseases ( $10^{\text {th }}$ version; ICD-10) code prefixes I60, I61, I63, I64, H34, I67, and G45; subsequent diagnoses of stroke or transient ischemic attack were compiled for all participants. All other diagnoses were based on information from assessments conducted during home visits and records from hospitals, general practitioners, and institutional care facilities. A physician comprehensively reviewed the digital medical charts of individuals.

There are problems in defining fall risk, as many studies fail to specify an operational definition, leaving room for interpretation. A fall is an unintentional event that results in the person coming to rest on the ground or another lower level (W19.9 code in the electronic health record). A fall was defined as the result of any event that caused the patient to end up on the ground against their will, according to the WHO definition [20]. We used "a clinical report in the electronic health record that a person had a fall risk or previous recurrent falls with or without any serious injury". If a patient is thought to be high risk by medical or nursing staff, allied health, or carers, such patients will be identified as a fall risk in the PIIC. This might include a mention of the patient's level of orientation and cognition, gait and balance, continence status, and number and types of prescribed medications, as well as number of diagnosis.

\section{Variables}

Sex: female (0) male (1)

Age: $<80$ years old (1), $\geq 80$ years old (2).

Number CCP criteria: $<4(0) \geq 4$ (1).

Charlson comorbidity index [21]. Short version.

Current medications were asked about during the home visit and confirmed in medical records. Polypharmacy (defined as $\geq 5$ daily medications): $<5$ (0), 5-9 (1), and $\geq 10$ (2). Oral anticoagulants (acenocumarol or warfarin) using the Rosendaal method for calculating Therapeutic Time in range [22] $\geq 60 \%$ or $<60 \%$, or new oral anticoagulants (NOACs). Antidepressants and/or sedating or other drugs affecting the neurological system. If there was a diagnosis of "atrial fibrillation, CHA2DS2VASC [23,24] HAS-BLED [25,26] scores were included.

Recurrent falls or fall risk: no (0), yes (1).

Hypertension not controlled by therapy ( $\geq 160 / 90 \mathrm{mmHg}$ ): no (0), yes (1). BP was measured as an average of separate follow-up measurements in the last six months.

Alcoholism abuse vs. dependence: no (0), yes (1) 
Citation: González-Henares MA, Clua-Espuny JL, Queralt-Tomas MLL, Campo-Tamayo W, Muria-Subirats E, et al. (2017) Relationship between Hemorrhagic Stroke and Mortality in Chronic Complex Outpatients: Results from a Community Cohort of Patients. J Aging Sci 5: 180. doi:10.4172/2329-8847.1000180

Page 3 of 9

Presence of cognitive impairment [27]: a disease-specific diagnosis of cognitive impairment, without specification of sub-type or severity, was used and mesured by the Pfeiffer test: $(0-2$ errors $)=$ intact intellectual functioning (1); $(\geq 3$ errors $)=$ mild to severe intellectual impairment (2).

Presence of disability: Barthel score [28] $\geq 60$ (1), $<60$ (2) or Rankin [29] $<4$ (1), $5(2))$ were used to assess dependence in ADL.

Socio-familiar risk: score on the Gijon [30] scale 10-14 (1) $\geq 15$ (2).

We conducted an intention-to-treat analysis. Patients were followed up from cohort entry as CCP to the first event occurrence (death), the end of the study period, or loss to follow-up. Categorical variables were expressed as frequencies (percentage) and quantitative variables as mean (standard deviation) or median (interquartile range). Demographic data were summarized using mean and SD or median and quartiles for continuous variables and percentages for categorical data. Data analysis information was extracted and the adjusted risk estimates and 95\% confidence intervals (CI) and all two-sided statistical tests were performed at the $5 \%$ significance level. Time-toevent analysis was performed using non-parametric methods like the Kaplan-Meier and log-rank test. To predict hazard ratios, mean survival time, and survival probabilities, multivariate Cox regression was used adjusting for the following baseline characteristics and confounding and predictive factors of each event: age, sex, Charlson index, factors in the CHA2DS2VASC and HAS-BLED scales, and active treatments. The variables were included in a multivariable model Cox to identify their influence on mortality. The non-hemorrhagic group and no stroke group were considered as the reference in all analyses. All analyses were performed using IBM SPSS version 19.0.

\section{Ethics Approval}

Ethics approval was granted by the Ethics Research Committee at Institut Primary Care Jordi Gol i Gurina (IDIAP), Health Department, Generalitat de Cataluña.

\section{Results and Discussion}

From 2013 to 2014, 932 CCP patients were included (52.3\% women) in the study. The baseline characteristics are shown in Table 1 and were not different from those previously described [3]. In the present study, the overall stroke incidence was $24.9 / 1000$ person-year. In total, 200 (75.1\%) stroke episodes had happened at baseline before patients were registered as CCP ((154 ischemic (79\%), 41 hemorrhagic (21.0\%)).

\begin{tabular}{|c|c|c|c|c|}
\hline CCP patients & No stroke & Hemorrhagic stroke & Ischemic stroke & $\mathbf{P}$ \\
\hline $\mathrm{N}(\%)$ & $675(72.4)$ & $69(7.4)$ & $188(20.17)$ & \\
\hline Age (average $\pm S D$ ) & $82.37 \pm 10.37$ & $81.62 \pm 9.5$ & $83.76 \pm 7.9$ & 0.071 \\
\hline $\begin{array}{l}\text { Percentage }>80 \text { years old } \\
\mathrm{n}(\%)\end{array}$ & $470(69.6)$ & $47(68.1)$ & $138(73.4)$ & 0.557 \\
\hline $\begin{array}{l}\text { Men } \\
\mathrm{n}(\%)\end{array}$ & $296(43.9)$ & $43(62.3)$ & $105(55.9)$ & 0.001 \\
\hline $\begin{array}{l}\text { CCP criteria number } \\
\text { (average } \pm \mathrm{SD} \text { ) }\end{array}$ & $3.72 \pm 1.17$ & $4.16 \pm 1.05$ & $4.23 \pm 1.18$ & 0.645 \\
\hline $\begin{array}{l}\text { Hypertension } \\
\mathrm{n}(\%)\end{array}$ & $549(81.3)$ & 65 (94.2) & $160(85.1)$ & 0.008 \\
\hline Hypertensionnot controled & $71(10.5)$ & $16(23.2)$ & $20(10.6)$ & 0.017 \\
\hline $\begin{array}{l}\text { Dyslipemia } \\
\text { n (\%) }\end{array}$ & $372(55.1)$ & $38(55.1)$ & $111(59.0)$ & 0.623 \\
\hline $\begin{array}{l}\text { Diabetes } \\
\mathrm{n}(\%)\end{array}$ & $371(55.0)$ & $29(42.0)$ & $94(50.0)$ & 0.08 \\
\hline $\begin{array}{l}\text { Atrial fibrillation } \\
\mathrm{n}(\%)\end{array}$ & $226(33.5)$ & $24(34.8)$ & 75 (39.9) & 0.269 \\
\hline $\begin{array}{l}\text { Ischaemic cardiopathy } \\
\mathrm{n}(\%)\end{array}$ & $135(20.0)$ & $17(24.6)$ & $44(23.4)$ & 0.454 \\
\hline $\begin{array}{l}\text { Peripheral artery disease } \\
n(\%)\end{array}$ & $107(15.9)$ & $10(14.5)$ & $32(17.0)$ & 0.872 \\
\hline Chronic kidney insuficiency & $87(12.9)$ & $10(14.5)$ & $19(10.1)$ & 0.503 \\
\hline $\begin{array}{l}\text { Heart failure } \\
\mathrm{n}(\%)\end{array}$ & $283(32.8)$ & $20(29.0)$ & $52(27.7)$ & 0.306 \\
\hline
\end{tabular}


Citation: González-Henares MA, Clua-Espuny JL, Queralt-Tomas MLL, Campo-Tamayo W, Muria-Subirats E, et al. (2017) Relationship between Hemorrhagic Stroke and Mortality in Chronic Complex Outpatients: Results from a Community Cohort of Patients. J Aging Sci 5: 180. doi:10.4172/2329-8847.1000180

Page 4 of 9

\begin{tabular}{|c|c|c|c|c|}
\hline $\begin{array}{l}\text { Charlson score } \\
\text { (average } \pm \text { SD) }\end{array}$ & $2.31 \pm 1.34$ & $3.10 \pm 1.37$ & $3.10 \pm 1.29$ & 0.998 \\
\hline $\begin{array}{l}\text { Stroke before CCP } \\
\mathrm{n}(\%)\end{array}$ & & $48(63.1)$ & $154(80.6)$ & $<0.001$ \\
\hline $\begin{array}{l}\text { Stroke after CCP } \\
\mathrm{n}(\%)\end{array}$ & & $28(36.9)$ & $37(19.4)$ & $<0.001$ \\
\hline $\begin{array}{l}\text { CHA2DS2VASCscore } \\
\text { (average } \pm \text { SD) }\end{array}$ & $4.61 \pm 1.08$ & $6.23 \pm 1.11$ & $5.83 \pm 1.32$ & 0.201 \\
\hline $\begin{array}{l}\text { Stroke risk/year average } \\
\text { (average } \pm \mathrm{SD} \text { ) }\end{array}$ & $5.88 \pm 2.25$ & $8.22 \pm 1.73$ & $7.87 \pm 2.26$ & 0.389 \\
\hline $\begin{array}{l}\text { HAS_BLED score } \\
\text { (average } \pm \text { SD) }\end{array}$ & $2.74 \pm 1.03$ & $4.14 \pm 0.88$ & $3.34 \pm 1.06$ & 0.002 \\
\hline $\begin{array}{l}\text { Bleeding risk/year } \\
\text { (average } \pm \mathrm{SD} \text { ) }\end{array}$ & $4.15 \pm 3.22$ & $8.91 \pm 3.25$ & $6.11 \pm 3.76$ & 0.002 \\
\hline $\begin{array}{l}\text { Chronic liver disease } \\
\mathrm{n}(\%)\end{array}$ & $37(5.5)$ & $4(5.8)$ & $10(5.3)$ & 0.989 \\
\hline $\begin{array}{l}\text { Daily medications number } \\
\text { (average } \pm S D \text { ) }\end{array}$ & $8.83 \pm 3.68$ & $8.06 \pm 3.33$ & $9.32 \pm 3.30$ & 0.007 \\
\hline $\begin{array}{l}\text { Polypharmacy } \geq 5 \\
n(\%)\end{array}$ & $626(92.7)$ & 65 (94.2) & 185 (98.4) & 0.005 \\
\hline $\begin{array}{l}\text { Polypharmacy } \geq 10 \\
\text { n (\%) }\end{array}$ & $299(44.3)$ & $18(26.1)$ & $83(44.1)$ & 0.011 \\
\hline $\begin{array}{l}\text { Cognitive impairment } \\
\mathrm{n}(\%)\end{array}$ & $220(32.6)$ & 30 (43.9) & $88(46.8)$ & 0.001 \\
\hline $\begin{array}{l}\text { Pfeiffer testscore } \\
\text { (average } \pm \mathrm{SD} \text { ) }\end{array}$ & $2.86 \pm 3.22$ & $3.2 \pm 3.48$ & $3.70 \pm 3.31$ & 0.278 \\
\hline $\begin{array}{l}\text { Barthel score } \\
\text { (average } \pm \mathrm{SD} \text { ) }\end{array}$ & $68.6 \pm 31.58$ & $59.2 \pm 31.0$ & $58.97 \pm 32.21$ & 0.961 \\
\hline $\begin{array}{l}\text { Barthel score }<60 \\
\mathrm{n}(\%)\end{array}$ & $215(31.9)$ & $33(47.8)$ & $95(50.5)$ & $<0.001$ \\
\hline $\begin{array}{l}\text { Fall risk } \\
\mathrm{n}(\%)\end{array}$ & $117(17.3)$ & $22(31.9)$ & $49(26.1)$ & 0.002 \\
\hline $\begin{array}{l}\text { Gijón score } \\
\text { (average } \pm S D \text { ) }\end{array}$ & $10.53 \pm 4.71$ & $10.57 \pm 1.81$ & $8.05 \pm 4.62$ & 0.177 \\
\hline $\begin{array}{l}\text { Antiaggregant treatment } \\
n(\%)\end{array}$ & $238(35.3)$ & $28(40.6)$ & 119 (63.3) & $<0.001$ \\
\hline $\begin{array}{l}\text { Anticoagulant treatment } \\
\mathrm{n}(\%)\end{array}$ & $191(28.3)$ & $17(24.6)$ & $62(33.0)$ & 0.275 \\
\hline $\begin{array}{l}\text { Statin treatment } \\
\mathrm{n}(\%)\end{array}$ & $294(43.6)$ & $32(46.4)$ & $97(51.6)$ & 0.146 \\
\hline $\begin{array}{l}\text { Uric acid treatment } \\
\mathrm{n}(\%)\end{array}$ & $106(15.7)$ & $16(23.2)$ & $28(14.9)$ & 0.272 \\
\hline
\end{tabular}


Citation: González-Henares MA, Clua-Espuny JL, Queralt-Tomas MLL, Campo-Tamayo W, Muria-Subirats E, et al. (2017) Relationship between Hemorrhagic Stroke and Mortality in Chronic Complex Outpatients: Results from a Community Cohort of Patients. J Aging Sci 5: 180. doi:10.4172/2329-8847.1000180

Page 5 of 9

\begin{tabular}{|l|l|l|l|l|}
\hline $\begin{array}{l}\text { Proton pump inhibitor treatment } \\
\mathrm{n}(\%)\end{array}$ & $445(65.9)$ & $52(76.8)$ & $15(77.1)$ & \\
\hline $\begin{array}{l}\text { Selective serotonin reuptake inhibitors (SSRIs) } \\
\mathrm{n}(\%)\end{array}$ & $186(27.6)$ & $24(34.8)$ & $70(37.2)$ & 0.004 \\
\hline $\begin{array}{l}\text { CNS depressant drugs } \\
\mathrm{n}(\%)\end{array}$ & $360(53.3)$ & $42(60.9)$ & $112(59.6)$ & 0.028 \\
\hline $\begin{array}{l}\text { Death } \\
\mathrm{n}(\%)\end{array}$ & $215(31.9)$ & $41(59.4)$ & $63(33.5)$ & 0.19 \\
\hline
\end{tabular}

Table 1: Baseline characteristics of CCP patients and stroke: ischemic vs. hemorrhagic.

During a mean follow-up period of 2.8 years, 65 (6.98\%) stroke episodes happened [37 (56.9\%) ischemic; 28 (43.1\%) hemorrhagic]. The annual crude hemorrhagic stroke rate was $23.5 / 100,000$ personyear. The percentage of hemorrhagic strokes almost doubled $(21.0 \%$ to 43.1) after diagnosis as CCP. Those that suffered a stroke after registration as CCP had more comorbidities ( $\mathrm{p}$ 0.012), higher scores in CHA2DS2VASC $(\mathrm{p}<0.001)$, HAS_BLED $(\mathrm{p}<0.001)$, a greater fall risk (40.9\% vs. $18.6 \%, \mathrm{p}<0.001)$, and higher mortality $(47.0 \%$ vs. $33.3 \%, \mathrm{p}$ $0.031)$ than those without a stroke episode.

\begin{tabular}{|l|l|l|l|}
\hline Variables & Hazard Ratio & $\mathbf{9 5 \%} \mathbf{C l}$ & $\mathbf{p}$ \\
\hline Age & 1.034 & $1.017-1.052$ & $<0.001$ \\
\hline Charlson score & 1.349 & $1.223-1.487$ & $<0.001$ \\
\hline Previous ischemic stroke & 17.2 & $11.9-24.66$ & $<0.001$ \\
\hline Atrial fibrillation & 1.389 & $1.037-1.862$ & 0.028 \\
\hline CHA ${ }_{2}$ SS $_{2}$ VAS \\
Score & 1.652 & $1.383-1.972$ & $<0.001$ \\
\hline HAS-BLED score & 1.148 & $1.158-1.738$ & $<0.001$ \\
\hline $\begin{array}{l}\text { Selective serotonin reuptake } \\
\text { inhibitors (SSRIs) }\end{array}$ & 1.354 & $1.007-1.822$ & 0.045 \\
\hline Fall risk & 1.401 & $1.010-1.942$ & 0.044 \\
\hline Pfeiffer score & 1.11 & $1.071-1.163$ & $<0.001$ \\
\hline Barthel score<60 & 2.706 & $2.028-3.611$ & $<0.001$ \\
\hline
\end{tabular}

Table 2: Significant factors consistently associated with incident hemorrhagic stroke at baseline in the univariate model.

The patients with hemorrhagic stroke were mostly men $(62.3 \%$, p $0.008)$, with more than the average number of CCP criteria $(4.1 \pm 1.0$, $\mathrm{p}$ 0.028) and higher scores in the Charlson index $(\mathrm{p}<0.001)$, CHA2DS2VASC $(\mathrm{p}<0.001)$, and HAS_BLED $(\mathrm{p}<0.001)$. These patients also had a higher prevalence of hypertension ( $\mathrm{p} 0.004)$ and worse control ( $\mathrm{p} 0.003$ ), more polypharmacy ( $\mathrm{p} 0.002)$, a higher prevalence ( $\mathrm{p}$ 0.034 ) of moderate dependence (Barthel $<60$ ), and a higher prevalence of fall risk ( $p$ 0.012). In total, $25 \%$ of hemorrhagic episodes happened among patients with previous ischemic stroke; the significant factors associated consistently with incident hemorrhagic stroke at baseline in univariate model are shown in Table 2. In the basic adjusted multivariate model, the significant factors were: age (HR 1.03, 95\%, CI 1.14-1.05, p 0.001), previous stroke (HR 13.54, 95\%, CI 9.23-19.81, $\mathrm{p}<0.001$ ), antiagreggant treatment (HR 1.97, 95\%, CI 1.21-3.21, p
0.006), anticoagulant treatment (HR 1.78, 95\%, CI 1.22-2.60, p 0.002), and Barthel score $<60$ (HR 1.43, 95\%CI 1.04-1.974, p 0.02).

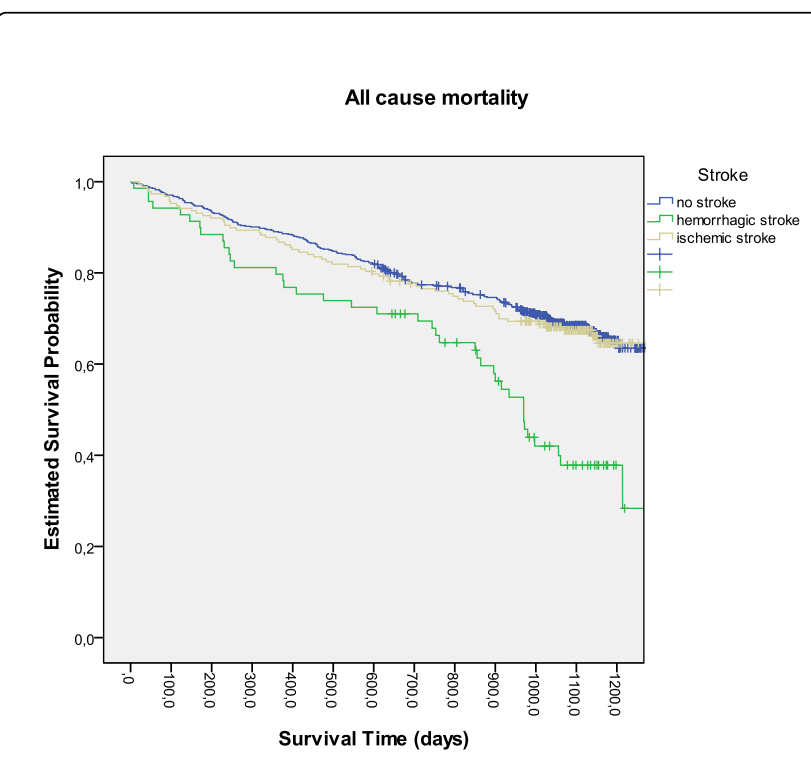

Figure 1: Kaplan-Meier estimates of survival during follow-up according to the type of stroke at baseline.

According to gender, severity (NIHSS men $8.3 \pm 7.3 \mathrm{vs}$. women 8.7 \pm 6.8, (p 0.816) was not significantly different. After discharge, the average Barthel score $(62.3 \pm 32.1$ vs. $70.2 \pm 31.2, \mathrm{p}<0.001)$ and Rankin score $(2.6 \pm 1.5$ vs. $3.1 \pm 1.4$, p 0.021$)$ were significantly lower among women as well as the presence of moderate dependence (Barthel $\leq 60$ men $43.1 \%$ vs. women $56.9 \%$ ). Also the percentage of cognitive impairment was higher than among men $(65.4 \%$ vs. $30.2 \%$, p 0.006$)$, with higher scores on the Pfeiffer test ( $p$ 0.007) and Gijon scale (0.020), and were more often users of CNS depressant drugs (84.6\% vs. $46.5 \%$, $\mathrm{p}$ 0.002). In the basic adjusted multivariate model, age, previous disability, and female gender were independent factors associated with poor functional outcome at discharge.

The overall mortality was significantly higher among those with hemorrhagic stroke $(59.4 \%$ vs. $32.2 \%, \mathrm{p}<0.001)$. The average survival time was significantly shorter (Figure 1) among those with hemorrhagic stroke. In the basic multivariate analyses, the outcome independent factors were: Charlson score (HR 1.13395\%, CI 1.043-1.23, p 0.003), cognitive impairment (Figure 2) [HR 1.05 95\%, CI 
Citation: González-Henares MA, Clua-Espuny JL, Queralt-Tomas MLL, Campo-Tamayo W, Muria-Subirats E, et al. (2017) Relationship between Hemorrhagic Stroke and Mortality in Chronic Complex Outpatients: Results from a Community Cohort of Patients. J Aging Sci 5: 180. doi:10.4172/2329-8847.1000180

Page 6 of 9

1.01-1.09, p 0.011], Barthel score <60 (HR 1.92 95\%, CI 1.47-2.50, $\mathrm{p}<0.001)$, age [HR $1.0395 \%$ CI $1.02-1.05, \mathrm{p}<0.001$ ], and heart failure (HR 1.82 95\%, CI 1.44-2.29, p<0.001). The case-fatality rates were $44 \%$ at 28 days and $57 \%$ at one year.

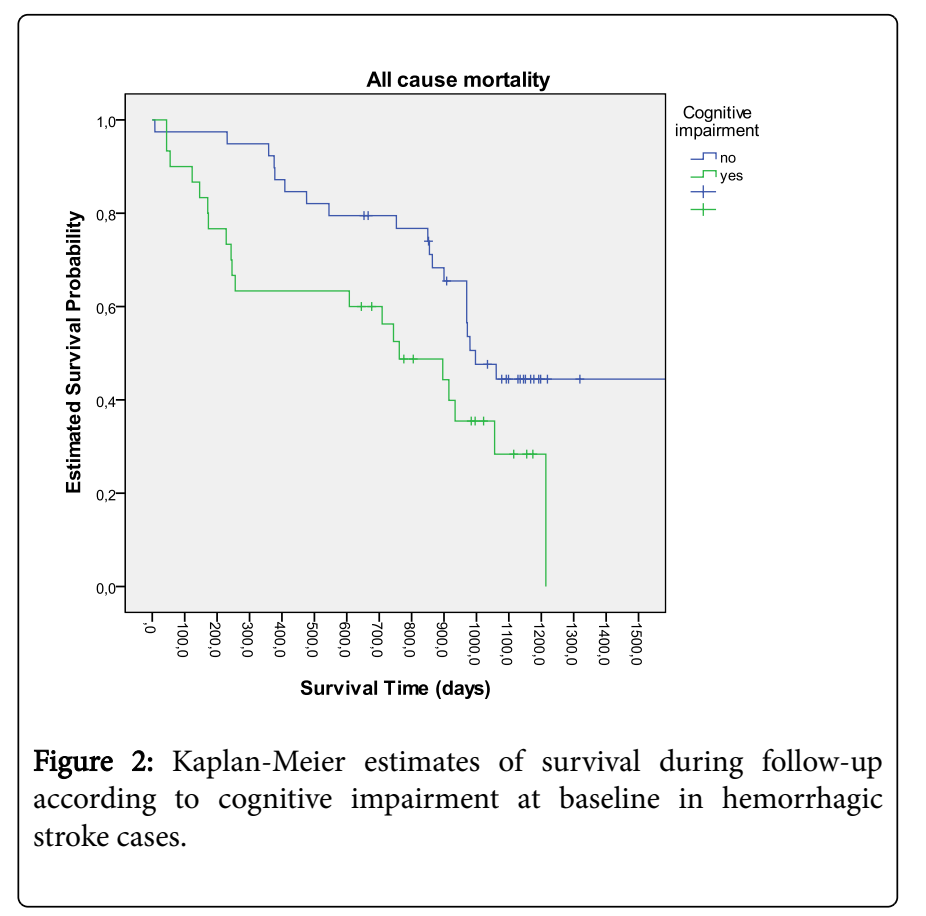

\section{Discussion}

This study describes some epidemiological differences in hemorrhagic strokes in the general population. Similarly to previous results [3], in CCP, there is an increased incidence associated with aging and the risk of ICH mortality appears to be marginally greater in men, but the women suffer more functional disability. The first step should be the prevention of ICH. Single explanatory variables associated to hemorrhagic stroke incidence were age, hypertension, previous stroke, antiagreggant and anticoagulant treatments and Barthel score $<60$, but we could not establish them as independent risk factors. Like in previous results [4] the older individuals become, less could be avoided the hemorrhagic stroke. The control of cardiovascular comorbidities, fall risk, and polypharmacy could be manageable clinically and related to prevention proposals but the possible impact on the outcome is an open question.

In this cohort, $25 \%$ of hemorrhagic episodes happened among patients with ischemic stroke at baseline. Following an acute stroke, breakdown of the blood brain barrier occurs, resulting in a friable intracranial vasculature. This breakdown theoretically increases the risk of intracerebral bleeding, specifically in the area of ischemia. The study provides interesting descriptive data about treating older patients on OAC. Antiplatelet drugs confer an increased risk of bleeding, but unfortunately, little data exist to suggest how long this friability lasts or what other factors may contribute [31]. Patients with polypharmacy had a significantly higher risk of major and medically relevant nonmajor bleeding than patients without polypharmacy [32]. In our study, $26.1 \%$ of hemorrhagic patients had polypharmacy $(\geq 10) ; 57.6 \%$ of hemorrhagic patients spent more time in the subtherapeutic INR range vs. $46.7 \%$ of ischemic cases, and had a significantly higher $(\mathrm{p}<0.001)$ bleeding risk/year than ischemic patients; the hemorrhagic patients had a higher incidence of falling (31.9\% vs. 19.2\%). It seems prudent to critically review medications and to stop concomitant treatment with medications with an increased risk of interactions, sedation, or orthostatic hypotension, if feasible. Further studies are needed to examine whether new oral anticoagulants can be used more safely in elderly patients receiving multiple drug treatments [32].

Given that the falls have come to be recognized as a major threat to the safety, health and independence of elderly persons [33], the use of the evaluation of fall risk in the community could improve knowledge translation into clinical practice. Eventually, for risk factor assessment to make a difference, all risk factors identified in the risk assessment need to be addressed in the care plans, and the care plans need to be acted on.

High SBP ( $\geq 160 \mathrm{mmHg}$ ) and atrial fibrillation appeared to be risk factors for incident stroke among very old people [34-37]. In the present study, SBP at least $160 \mathrm{mmHg}$ was not associated with incident stroke in the univariate model, but was associated with higher mortality risk. We highlight the importance of BP management in patients with risk factors for intracerebral hemorrhage. Some of these factors may increase mortality risk, individually or collectively as a measure of geriatric multimorbidity. It is possible that mortality depends on other factors [38] such as hemorrhage size. Our study includes very old people with cognitive and/or physical disability, and whether hypertension truly increases stroke risk in representative populations of very old people remains unclear because the prevalence of SBP $\geq 160 \mathrm{mmHg}$ is similar (12.0\% vs. $11.2 \%$, p 0.407) [39-41] in people with and without ADL dependence and cognitive impairment. Confounding factors may obscure the association between BP and incident stroke unless accounted for. However, women with cognitive impairment could be a target population for care interventions.

Researchers have arbitrarily chosen various cut-off points in the definition of polypharmacy. Therefore, an elderly patient with at least two disease states will usually exceed this arbitrary threshold. In total, $91.6 \%$ of CCP had $\geq 4$ active medications, $52.4 \%$ between $4-9$, and $32.9 \% \geq 10$. The average use of 9.0 daily medications by our study participants is consistent with the existing literature [42,43], but it is high and concerning. On the other hand, polypharmacy is not just the use of multiple medications, but also and/or the administration of more medications than are clinically indicated, representing unnecessary drug use $[44,45]$. In our study, the most used therapeutic groups are coincident with those commonly involved in inappropriate prescription: treatment of peptic ulcers, cardiovascular medications, antidepressants, and hypnotics [46]. Future research should document more evidence regarding the reality of rationing in CCP, adverse drugdrug interactions, and the increased risk of falling.

There is confusion over whether the risk of hemorrhagic stroke is increased in people taking statins. Several meta-analyses have shown either no increase, or a non-significant increase, in the risk of hemorrhagic stroke when statins are used for primary or secondary prevention $[47,48]$. Despite having similar rates of cardiovascular comorbidities, hemorrhagic patients who receive statins are significantly more likely to survive after stroke onset compared with non-users [4] and continuing statins after ICH may not only be safe but could also be beneficial [49]. In our study, statins were the second drug in terms of frequency of prescription in $46.4 \%$ of hemorrhagic patients. The decision to stop or continue [50] statin treatment in patients after hemorrhagic stroke remains controversial, and needs randomized trials investigating statin use in patients with acute intracerebral hemorrhage to inform patient management. 
Citation: González-Henares MA, Clua-Espuny JL, Queralt-Tomas MLL, Campo-Tamayo W, Muria-Subirats E, et al. (2017) Relationship between Hemorrhagic Stroke and Mortality in Chronic Complex Outpatients: Results from a Community Cohort of Patients. J Aging Sci 5: 180. doi:10.4172/2329-8847.1000180

Page 7 of 9

Eventually, the fragmented care contributes to the overall decline of elders living in any environment [51]. Coordination among clinicians and caregivers and the periodic critical review of all the medications taken, and establishing a close relationship with the family, primary care physician, and social workers are essential. After happening the intracerebral haemorrhage, an increase in favourable functional outcome rather than simple survive and the decisions about the direction of care could be influenced by the previous good care of these variables.

In the unadjusted analysis, the patients who had a previous ischemic stroke were at a significantly higher risk of death (Figure 3) if they had been registered as a fall risk. The fall risk was higher (31.9\% vs. $19.2 \%$, p 0.012) among those with hemorrhagic stroke, but without an impact on long-term survival. Routine clinical questioning about previous falls may, thus, be a key strategy to identify at-risk individuals so preventive interventions can be introduced.

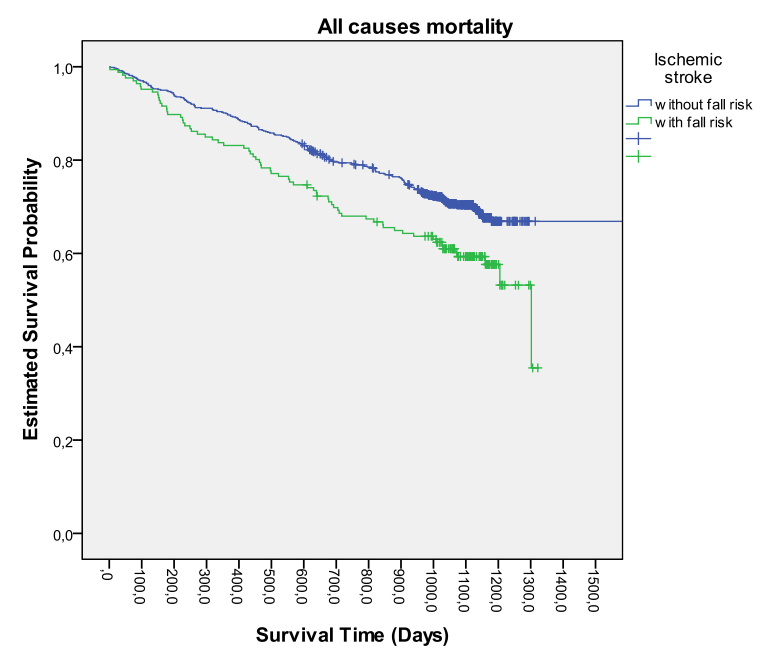

Figure 3: Kaplan-Meier estimates of survival during follow-up of ischemic stroke cases according to the presence of fall risk or not at baseline.

The percentage of polypharmacy ( $\geq 10$ active medications) was associated to higher mortality in the presence of a fall risk (Figure 4), but without a difference in the average Charlson score or prevalence of comorbidities. We also found a higher percentage of cases using SSRIs among those with a fall risk, but without difference ( $p$ 0.2211) in mortality risk. Isolation and loneliness have been shown to be a risk factor for falls. The percentage in our study was $22.3 \%$ among people $\geq$ 75 years old.

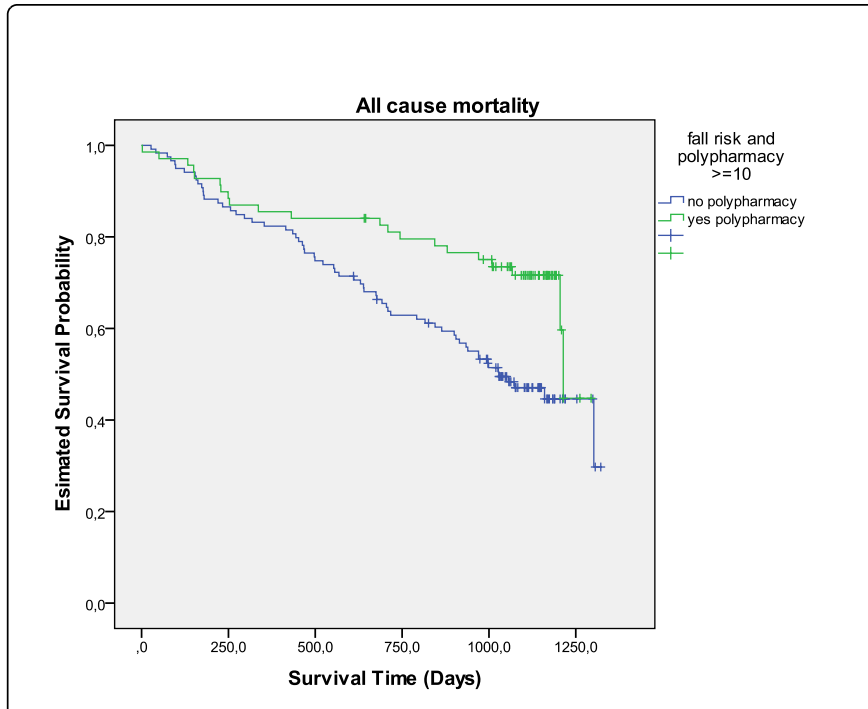

Figure 4: Kaplan-Meier estimates of survival during follow-up of stroke cases according to the presence of polypharmacy $(\geq 10)$ or not at baseline.

\section{Acknowledgement}

The authors thank the Research Group Ebrictus participants (www.ictusandstroke.com).

González-Henares MA has received project and fellowship grants from the Research Institut Primary Care Jordi Gol i Gurina (IDIAP) of Catalonia (Spain).

\section{References}

1. Reeve J, Blakeman T, Freeman G, Green LA, James PA, et al. (2013) Generalist solutions for complex problems: generating practice-based evidence: the example of managing multi-morbidity. BMC Family Practice 14: 112.

2. http://www.kingsfund.org.uk/time-to-think-differently/trends/diseaseand-disability/long-term-conditions-multi-morbidity.

3. Clua-Espuny JL, Garcés-Redondo M, Lucas-Noll J, Panisello-Tafalla A, Queralt-Tomas L, et al. (2014) Stroke epidemiology, survival and disability in a Mediterranean population according to Malmgren's criteria. Ebrictus cohort. Ann Vasc Med Res 1: 1004.

4. Gonzalez-Henares MA, Clua-Espuny JL, Gil-Guillen VF, Panisello-Tafalla A, Queralt-Tomas ML, et al. (2016) Incidence and preventability of haemorrhagic strokes. Results of the Ebrictus register. Rev Neurol 62: 385-395.

5. Islam MS, Anderson CS, Hankey GJ, Hardie K, Carter K, et al. (2008) Trends in incidence and outcome of stroke in Perth, Western Australia during 1989 to 2001: the Perth Community Stroke Study. Stroke 39: 776-782.

6. Huhtakangas J, Tetri S, Juvela S, Saloheimo P, Bode MK, et al. (2011) Effect of increased warfarin use on warfarin-related cerebral hemorrhage: a longitudinal population-based study. Stroke 42: 2431-2435.

7. Flaherty ML, Kissela B, Woo D, Kleindorfer D, Alwell K, et al. (2007) The increasing incidence of anticoagulant-associated intracerebral hemorrhage. Neurology 68: 116-121.

8. Khellaf M, Quantin C, d'Athis P, Fassa M, Jooste V, et al. (2010) Ageperiod-cohort analysis of stroke incidence in Dijon from 1985 to 2005. Stroke 41: 2762-2767. 
Citation: González-Henares MA, Clua-Espuny JL, Queralt-Tomas MLL, Campo-Tamayo W, Muria-Subirats E, et al. (2017) Relationship between Hemorrhagic Stroke and Mortality in Chronic Complex Outpatients: Results from a Community Cohort of Patients. J Aging Sci 5: 180. doi:10.4172/2329-8847.1000180

Page 8 of 9

9. Benatru I, Rouaud O, Durier J, Contegal F, Couvreur G, et al. (2006) Stable stroke incidence rates but improved case-fatality in Dijon, France, from 1985 to 2004 . Stroke 37: 1674-1679.

10. Torppa J, Sivenius J, Tuomilehto J, Immonen-Raiha P, Kaarisalo M, et al. (2004) Continuous 15- year decrease in incidence and mortality of stroke in Finland: the FINSTROKE study. Stroke 35: 420-425.

11. Crichton SL, Bray BD, McKevitt C, Rudd AG, Wolfe CDA (2016) Patient outcomes up to 15 years after stroke: survival, disability, quality of life, cognition and mental health. JNeurol Neurosurg Psychiatry 87: 1091-1098.

12. Vermeer SE, Algra A, Franke CL, Koudstaal PJ, Rinkel GJ (2002) Longterm prognosis after recovery from primary intracerebral haemorrage. Neurology 59: 205-209.

13. Muir SW, Gopaul K, Montero Odasso MM (2012) The role of cognitive impairment in fall risk among older adults: a systematic review and metaanalysis. Age Ageing 41: 299-308.

14. Tinetti ME, Fried TR, Boyd CM (2012) Designing health care for the most common chronic condition - multimorbidity. JAMA 307: 2493-2494.

15. http://www.termcat.cat/ca/Diccionaris_En_Linia/160/

16. Rost N, Smith E, Chang Y, Snider R, Chanderraj R, et al. (2008) Prediction of Functional Outcome in patients with primary intracerebral hemorrhage: the FUNC score. Stroke 39: 2304-2309.

17. Hemphill JC III, Bonovich D, Besmertis L, Manley G, Johnston S (2001) The ICH Score: A Simple, Reliable Grading Scale for Intracerebral Hemorrhage. Stroke 32: 891-897.

18. Cheung RTF, Zou L (2003) Use of the Original, Modified, or New Intracerebral Hemorrhage Score to Predict Mortality and Morbidity After Intracerebral Hemorrhage. Stroke 34: 1717-1722.

19. Zahuranec DB, Brown DL, Lisabeth LD, Gonzales NR, Longwell PJ, et al. (2007) Early care limitations independently predict mortality after intracerebral henorrhage. Neurology 68: 1651-1657.

20. http://www.who.int/ageing/publications/Falls_prevention7March.pdf.

21. Charlson M, Pompei P, Ales KL, McKenzie CR (1987) A new method of classyfing prognostic comorbidity in longitudinal studies: development and validation. J Chron Dis 40: 373-383.

22. Schmitt L, Speckman J, Ansell J (2003) Quality assessment of anticoagulation dose management: comparative evaluation of measures of time-in-therapeutic range. J Thromb Thrombolysis 15: 213-216.

23. Gage BF, Waterman AD, Shannon W, Boechler M, Rich MW, et al. (2001) Validation of clinical classification schemes for predicting stroke: results from the National Registry of Atrial Fibrillation. JAMA 285: 2864-2870.

24. Pamukcu B, Lip GY, Lane DA (2010) Simplifying stroke risk stratification in atrial fibrillation patients: implications of the CHA2DS2-VASc risk stratification scores. Age Ageing 39: 533-535.

25. Pisters R, Lane DA, Nieuwlaat R, De Vos CB, Crijns HJ, et al (2010) A novel user-friendly score (HAS-BLED) to assess 1-year risk of major bleeding in patients with atrial fibrillation: the Euro Heart Survey. Chest 138: 1093-1100.

26. Lip GY (2011) Implications of the CHA2DS2-VASc and HAS-BLED scores for thromboprophylaxis in atrial fibrillation. Am J Med 124: 111-114.

27. Pfeiffer E (1975) A short portable mental status questionnaire for the assessment of organic brain deficit in elderly patients. J Am Geriatr Soc 23: 433-441.

28. Van Exel NJ, Scholte op Reimer WJ, Koopmanschap MA (2004) Assessment of post-stroke quality of life in cost-effectiveness studies: The usefulness of the Barthel Index and the EuroQoL-5D. Qual Life Res 13: 427-433.

29. Carod-Artal F J (2004) Specific scales for rating quality of life after stroke. Rev Neurol 39: 1052-106.

30. García-González JV, Díaz-Palacios E, Salamea A, Cabrera D, Menéndez A, et al. (1999) Evaluación de la fiabilidad y validez de una escala de valoración social en el anciano. Aten Primaria 23: 434-40.
31. Chen PC, Lip GYH, Yeh G, Lin HJ, Chie KL (2015) Risk of bleeding and stroke with oral anticoagulation and antiplatelet therapy in patients with atrial fibrillation in Taiwan: anationwide cohort study. PLoS One 10: e0125257.

32. Leiss W, Méan M, Limacher A, Righini M, Jaeger K, et al. (2015) Polypharmacy is Associated with an Increased Risk of Bleeding in Elderly Patients with Venous Thromboembolism. J Gen Intern Med 30: 17-24.

33. Marks R (2014) Falls Among the Elderly: Multi-factorial Communitybased Falls-Prevention Programs. Aging Sci 2: e109.

34. Hörnsten C, Weidung B, Littbrand H, Carlberg B, Nordström P, et al. (2016) High blood pressure as a risk factor for incident stroke among very old people: a population-based cohort study. J Hypertens 34: 2059-2065.

35. Clua-Espuny JL, Bosch-Princep R, Roso-Llorach A, López-Pablo C, Giménez-Garcia E, et al. (2014) Diagnosed, undiagnosed and overall atrial fibrillation: Prevalence and patient profile among people over 60 years in Baix Ebre, Spain. AFABE Study. Cardiovascular System.

36. Clua-Espuny JL, Panisello-Tafalla A, Lopez-Pablo C, Lechuga-Duran I, Bosch-Princep R, et al. (2014) Atrial fibrillation and cardiovascular comorbidities, survival and mortality: A real-life observational study. Cardiol Res 1: 12-22.

37. Clua-Espuny JL, González-Henares MA, Queralt-Tomas MLL, PaniselloTafalla A, Campo-Tamayo W, et al. (2016) Atrial Fibrillation and cognitive impairment: a growing association. Occurrence of death among chronic complex outpatients. EC Cardiology 2: 226-239.

38. Hemphill JC, Bonovich DC, Besmertis L, Manley GT, Johnston SC (2001) The ICH Score. Stroke 32: 891-897.

39. González-Henares MA, Clua-Espuny JL, Queralt-Tomas MLL, PaniselloTafalla A, Ripolles-Vicente R, et al. (2016) Falls risk and mortality among chronic complex outpatients: results of community-based prospective study. Gerontol Geriatr Res 2: 1024.

40. Panisello-Tafalla A, Clua-Espuny JL, Gil-Guillen VF, González-Henares A, Queralt-Tomas ML, et al. (2015) Results from the Registry of Atrial Fibrillation (AFABE): Gap between prevalence of undiagnosed and registered atrial fibrillation in adults: ineffectiveness of antivitamin $\mathrm{K}$. Cardiology subject area of BioMed Research International.

41. Clua-Espuny JL, González-Henares MA, Queralt-Tomas MLL, GilGuillen VF on behalf of the Ebrictus Research Group (2016) Polypharmacy and Mortality among Chronic Complex outpatients: Results of community-based prospective study. Int J Med Res Pharm Sci 3: 59-74.

42. Fulton MM, Allen ER (2005) Polypharmacy in the elderly: a literature review. J Am Acad Nurse Pract 17: 123-132.

43. Clague F, Mercer SW, McLean G, Reynish E, Guthrie B (2016) Comorbidity and polypharmacy in people with dementia: insights from a large, population-based cross-sectional analysis of primary care data. Age Ageing 46: 33-39.

44. O'Dwyer M, Peklar J, McCallion PH, McCarron M, HenmanMC (2016) Factors associated with polypharmacy and excessive polypharmacy in older people with intellectual disability differ from the general population: a cross-sectional observational nationwide study. BMJ open 6: $\mathrm{e} 010505$.

45. Tjia J, Velten SJ, Parsons C, Valluri S, Briesacher BA (2013) Studies to reduce unnecessary medication use in frail older adults: a systematic review. Drugs Aging 30: 285-230.

46. Bregnhøj L, Thirstrup S, Kristensen MB, Bjerrum L, Sonne J (2007) Prevalence of inappropriate prescribing in primary care. Pharm World Sci 29: 109-115.

47. Hackam DG, Woodward M, Newby LK, Bhatt DL, Shao M, et al. (2011) Statins and intracerebral hemorrhage: collaborative systematic review and meta-analysis. Circulation 124: 2233-2242.

48. McKinney JS, Kostis WJ (2012) Statin therapy and the risk of intracerebral hemorrhage: a meta-analysis of 31 randomized controlled trials. Stroke 43: 2149-2156.

49. Flint AC, Conell C, Rao VA, Klingman JG, Sidney S, et al. (2014) Effect of statin use during hospitalization for intracerebral hemorrhage on mortality and discharge disposition. JAMA Neurol 71: 1364-1371. 
Citation: González-Henares MA, Clua-Espuny JL, Queralt-Tomas MLL, Campo-Tamayo W, Muria-Subirats E, et al. (2017) Relationship between Hemorrhagic Stroke and Mortality in Chronic Complex Outpatients: Results from a Community Cohort of Patients. J Aging Sci 5: 180. doi:10.4172/2329-8847.1000180

Page 9 of 9

50. Bustamante A, Montaner J (2013) Statin therapy should not be discontinued in patients with intracerebral hemorrhage. Stroke 44: 2060-2061.
51. McAllister A, Beaty JA (2016) Aging Well: Promoting Person-Directed Care. J Aging Sci 4: 164 